\title{
The use of fibre-reinforced polymers (FRP) in bridges as a favourable solution for the environment
}

\author{
Artur Żyjewski ${ }^{1, *}$, Jacek Chróścielewski ${ }^{1}$, and Lukasz Pyrzowski ${ }^{1}$ \\ ${ }^{1}$ Dep. of Mechanics of Materials and Structures, Faculty of Civil and Environmental Engineering, \\ Gdansk University of Technology, G. Narutowicza 11/12, 80-233 Gdańsk, Poland
}

\begin{abstract}
The purpose of this article is to show the modern engineering, in which sustainability and taking care of ecology play a significant role. The authors are focused on FRP composite materials and their applications in civil engineering. Case studies showing renovation and design of new bridges with the use of FRP are presented and discussed to clarify benefits, which this solution provides. Main advantages of FRP materials in comparison with traditional ones, like concrete or steel are showed. The environmental impact of composites is described with respect to all life cycle of a product. Furthermore, some forms of waste management are covered. Last part of the paper refers to scientific description of the pedestrian bridge made of FRP, which was realized under the Fobridge research grant. The group of researchers headed by professor Chróścielewski from Gdansk University of Technology has developed a design solution of the pedestrian bridge manufactured in one production cycle. Moreover, the footbridge construction contains a significant share of a recyclable material commonly called PET. The article contains main characteristics of the structure and production process based on the resin infusion.
\end{abstract}

\section{Introduction}

Achievements in the discipline of materials science and engineering allow us to take a new direction, in which the traditional building materials, such as steel or reinforced concrete can be replaced by fibre-reinforced polymers (FRP). About $26 \%$ of FRP composites world production is applied in the construction industry, [1]. It means that a large part of market share distribution is dedicated to mentioned area, see Fig. 1. The use of FRP materials in civil engineering have been developed mainly in bridge structures, [2]. The fibre-reinforced polymers first applications were realized in rehabilitation and strengthening of ageing structures. Afterward, the FRP began to be used as a construction material, thereby as a good substitution for steel or concrete. One of the most typical solution of strengthening may be performed by bonding adhesive sheets or plates made of FRP into the soffit of deteriorated concrete or metallic elements to improve flexural

*Corresponding author: artzyjew@student.pg.gda.pl 
resistance, $[2,3]$. The example of rehabilitation may be a replacement of degraded concrete decks on FRP ones in ageing steel-concrete bridges. Additional advantage of this solution is obtaining less weight of a structure. The first pedestrian bridge made of FRP was built in 1975 in Tel Aviv, Israel, whereas the first road bridge was created in 1995 in Stonehouse (Surrey), UK (Bonds Mill Lifting) [4].



Fig. 1. Market share distribution of fibre-reinforced polymers [1].

Material properties like low volume weight and relatively high strength and stiffness at the same time, are the main aspects for which the FRP composites are increasingly being used in structural applications. Nowadays, not only mechanical parameters of materials have important role in constructions but sustainability of solutions too. To effectively evaluate negative impacts on environment, it is necessary to analyse the entire life cycle of a structure. This analysis includes three main phases: the production phase, the use phase and the end of life phase. Different activities in each phases generate potential sources of environmental impact. It can be, for instance, material extraction, transportation of materials/waste/employees during the construction, on-site activities, traffic disruption and detours during maintenance and construction activities [5]. Summing up, aspects like time or construction cost, energy consumed with production process and carbon emission pose main environmental threat.

\section{Sustainability in terms of bridge constructions}

Decreasing an impact on the environment caused by bridge constructions is one of the propositions for modern engineering. Current priorities have been established in the European PANTURA Project. The PANTURA is a research program co-financed by the European Commission. The main aim of the project is to elaborate new solutions for more efficient maintenance works, to improve off-site productions and to make bridges more ecological. In general, the efficiency should provide reducing time of construction process, use of materials and minimizing environment pollution. All activities are strongly related with sustainable development [6], which has been defined by World Commission on Environment and Development in 1987.

“..Sustainable development is a process of change in which the exploitation of resources, the direction of investments, the orientation of technological development, and 
institutional change are all in harmony and enhance both current and future potential to meet human needs and aspirations."

Therefore, the ideal material has to guarantee recovery of resources and energy. Moreover, this ideal material should not pollute the environment during its life cycle [6]. In the construction industry a large amount of energy consumption and resource utilization cause contamination problems and these factors should be limited at first. The proposed solution is to minimize time of each phases in a construction process by utilization of lighter and stronger materials, see $[1,2,5]$. A lot of research studies have revealed different advantages with respect to replacement of steel or concrete by composite materials made of fiber-reinforced polymers. Because of very good mechanical properties, FRP composites may have potential benefits for sustainable solutions. The application of bridge structural elements made of fiber-reinforced polymer can provide reduction about $80 \%$ of total weight comparing with concrete structures and about $30 \%$ taking into account steel ones [1]. Light weight enables fast transportation, allows to reduce traffic disruption, and the installation process become quick and simple. In addition, the carbon emission is also reduced due to traffic reduction. Besides, FRP components require less maintenance work because of high strength and corrosion resistance. All these mentioned aspects provide solutions, which aim is to reach low life cycle cost of the structure [2]. The only disadvantage for widespread application is usually higher initial cost as compared with conventional materials. But this aspect still changes, due to the fact that prices of FRP component materials tend to decrease.

Furthermore, during the production process the energy consumption and carbon emission is relevant higher in case of FRP materials. In spite of these objections FRP composites seems to be environmentally friendly due to reduction of mentioned disadvantages in other life cycle phases, which are: construction, maintenance, and demolition. It is worth to note, that cumulative energy demand for a FRP production process is strictly depend on manufacturing methods and fibre types [1,5]. Table 1 shows various values energy demand in different production techniques. Fig. 2 depicts the comparison of different materials in connection with energy consumption during fabrication process.

Table 1. Cumulative energy demand (CED) [1].

\begin{tabular}{|c|c|}
\hline Material & CED $(\mathbf{M J} / \mathbf{k g})$ \\
\hline Sheet molding compound (SMC) & $3.5-3.8$ \\
\hline Resin transfer molding (RTM) & 12.8 \\
\hline Pultrusion & 3.1 \\
\hline Autoclave & 21.9 \\
\hline Injection molding & $21.1-29.9$ \\
\hline
\end{tabular}

\section{Examples of FRP application in bridge structures}

The paragraph presents some case studies. The aim of this overview is to evaluate environmental impact of FRP materials. Two examples are described. 


\subsection{Bridge renovation}

First example presents a case of bridge renovation. It involves substitution of a deteriorated bridge deck by a new structure made of FRP [5]. The study concerns the small bridge over the Rokan River in Sweden. The structure was built in 1948 as a simple supported system of $12 \mathrm{~m}$ span length and $6.5 \mathrm{~m}$ deck width. It contains two steel girders at $3.6 \mathrm{~m}$ spacing. Before renovation the deck was made of a concrete slab without any form of connection with the beams. The expertise from 2002 showed, that the ageing bridge needed a refurbishment. The steel girders were in good conditions. The maintenance work involved replacement of the existing deck, installation of a new barriers and creation of a new surface. Alternative solution was proposed in 2012 during the FRP bridges conference organized in London. The considerations were related to replacing the old bridge deck with a new element made of FRP composites. The analysis included a comparison of all construction activities performed in year 2002 with the proposed alternative solution. The following factors were included during assessment: duration and frequency of work performed, and traffic disturbance caused by these activities.

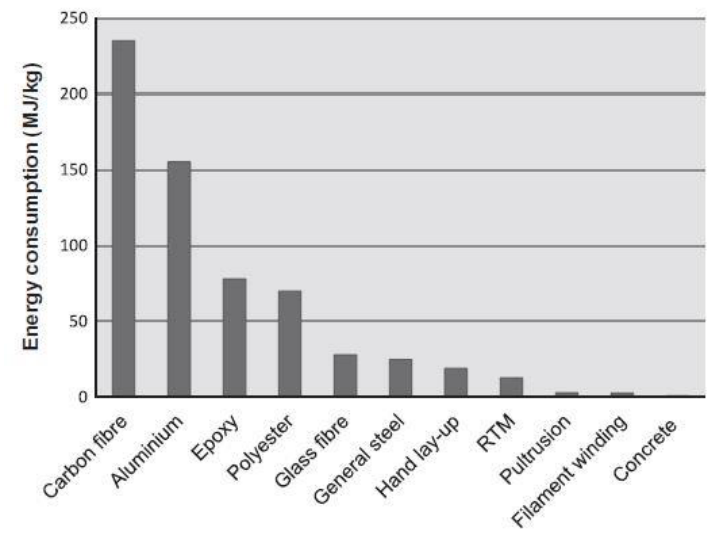

Fig. 2. Energy consumption for production of different materials and manufacturing processes [5].

The carried out investigation shows, that time needed to manufacture a new deck made of FRP is significantly shorter, around two times, in comparison with the production of a concrete slab. This means, that the traffic disturbance would be lower because of diminished temporary closure of the road. The alternative rout in this case is $16 \mathrm{~km}$ longer.

In case of the FRP solution, a maintenance works would only concern a replacement of a finished road surface, which could be made from a polymer concrete, typical in such applications. Time needed to accomplish this work is assumed as 24 hours. Such operation should be repeated each 20 years. In case of the traditional solution, it is required to remove and replace insulation and bituminous pavement. Time needed to perform these maintenance works was estimated at 24 hours for replacement of the asphalt and 2 weeks for insulation replacement. In both cases, the superstructure made of FRP composite and the traditional bridge deck, it is necessary to close only one lane to realize all mentioned tasks.

To sum up, the traditional solution causes more disrupted periods during entire lifecycle. The consequence of this, is a diversion of the traffic and finally higher carbon emission. Additionally, total carbon emission generated during entire life-cycle of both bridge structures were compared. Three factors were included in the assessment: production, transportation and traffic detours. The overall results also prove that higher carbon emission is produced in the case of bridge made of traditional materials (90 132 $\mathrm{kgCO} 2$ ). Total carbon emission for the FRP structure is $72059 \mathrm{kgCO} 2$. It is worth to note, 
that the carbon emission related to traffic detour will depend on their intensity. The analysed bridge is located in a rural area along a local road.

\subsection{Bridge replacement}

Second example is based on the replacement project of nineteenth-century highway bridge in North London. It focuses on an environmental impact of fibre reinforced polymers applications in bridges, especially on carbon emission during their entire lifecycle [2]. Two structural solutions are considered. Both are a simply supported single span of $12 \mathrm{~m}$ length and $12 \mathrm{~m}$ deck width. The difference between two choices is a material used for a construction. First one assumes the use of FRP composites and second one a prestressed concrete. The optional cross sections in analysed bridge are schematically presented in a fig. 3 .

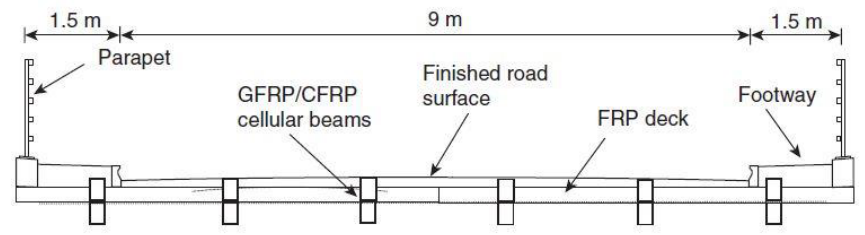

(a) FRP option

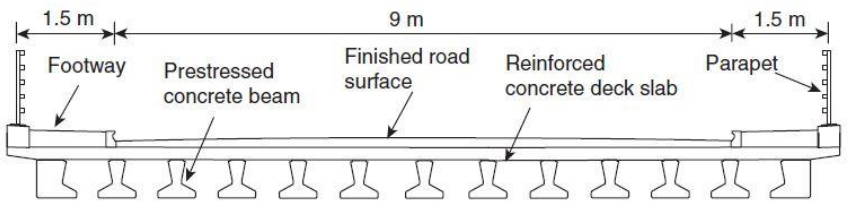

(b) Prestressed concrete option

Fig. 3. Optional cross sections in analysed bridge [2].

Both solutions are designed for full highway traffic on both lanes. The carbon emission from three different sources is taken into account during the analysis. The following factors are considered: embodied carbon of any new materials/products, different transportation types (transportation of workers, materials or products, and waste disposal) and traffic diversions. All of these source are considered into three life cycle phases: demolition of the existing bridge, construction and maintenance of a new superstructure. The embodied energy for FRP and steel reinforced concrete is estimated using tables from the Inventory of Carbon and Energy (ICE ver. 1.6a), [7]. In case of glass-fibre reinforced polymer, the value of embodied energy is very limited, because it is a relatively new material in civil engineering application. The quoted value from the ICE table is $100 \mathrm{MJ} / \mathrm{kg}$, but for this investigation it is changed after consulting with one of the major GRP producer in Europe, whose GRP embodied energy is assumed as $33 \mathrm{MJ} / \mathrm{kg}$. An average value is taken as the most objective and representative value for the study. For the reinforced concrete the embodied energy is calculated with a following formula [7]:

$$
E E=2,12(E E R C+0,26 n / 25)
$$

Where, the value of 0,26 means the use of $1 \mathrm{MJ} / \mathrm{kg}$ for each $25 \mathrm{~kg}$ of the steel per $1 \mathrm{~m}^{3}$ of concrete. EERC is related with a compressive strength class of concrete. For instance, the embodied energy for $\mathrm{C} 30 / 37$ is $1,08 \mathrm{MJ} / \mathrm{kg}$. As can be seen, production of the $1 \mathrm{~kg}$ of 
GRP requires much more of the energy use, what means more carbon emission into the environment. Below is the definition of the embodied energy, which is published in [7].

“...The embodied energy (carbon) of a building material can be taken as the total primary energy consumed over its life cycle. This would normally include extraction, manufacturing and transportation. Ideally the boundaries would be set from the extraction of raw materials until the end of the products lifetime."

The transportation of the materials depended on their availability. Traditional materials like steel or concrete can be purchased in local supplies, while companies manufacturing FRP structures are still limited. A transportation distance from supplies/landfills to a construction site for reinforced concrete is assumed to be 10 miles. In case of FRP composites, a water transport from Denmark is considered.

A daily traffic volume, distance and period of disruption are relevant factors in terms of the carbon emission produced during traffic diversion. Time needed to erect a bridge depend on specific construction method, for a FRP system is assumed to be 14 days and for a prestressed concrete structure approximately 85 days.

This case study demonstrates that carbon emission for both cases is similar and that the biggest carbon emission comes from traffic diversions. Considering the last factor, the FRP has an environmental advantage because of shorter time of construction period. Moreover, future improvements for composite materials should decrease theirs embodied emissions.

\section{Waste management during the last phase of life-cycle}

The FRP composites belong mainly to a group of thermosetting (thermoset) polymers. This means that during the process of chemical reactions called polycondensation, polymerization, or curing, the resin becomes rigid. When the thermosetting polymer are cured once, cannot be remelted or reformed. Relatively good mechanical properties of FRP, makes them an interesting alternative for traditional materials in civil applications. On the other hand the same properties make the recycling process more difficult and provide limited ways of the waste management.

Because of the economic aspects, the most popular form to manage of FRP waste is to disposal it on the landfills. However, landfills areas and raw materials are limited. To protect the environment, it is necessary to use methods of used materials recycle. In general, two categories of the recycling process can be distinguished. First group includes all these methods, in which the mechanical techniques are implemented. Second group is related with the incineration methods for recovery of the embodied energy from waste materials [8]. However, if the FRP composites include glass fibres, the incineration will not be so effective, because fibres are incombustible and consume approximately $1.7 \mathrm{MJ}$ per kilogram of glass-fibre content [1]. Despite of this disadvantage, the incineration is still the most suggested method of recycling. The incineration may be realized, for example, in cement kilns. It has been proved that during the incineration process of unsorted plastics is possible to recovery more than 8000 thermies per ton, [9] (1 thermie is approximately $4.1855 \times 10^{\wedge} 6$ joules). There are three incineration methods of FRP: pyrolysis, fluidizedbed processing and chemical treatment. The specified methods allow to retrieve individual carbon fibres in CFRPs or glass fibres in GFRPs. The purpose of mechanical processes is to use technique of crushing, milling and/or shredding FRP material into small pieces, from $100 \mathrm{~mm}$ to $50 \mu \mathrm{m}$. These methods can reduce the mechanical properties of FRPs up to $50 \%$. Therefore, the final product may be used as a fillers for producing panels, mortar and asphaltic concrete. The mechanical methods are mainly used in case of GFRPs composites. Due to the techniques of comminution, entire fibres are impossible to reclaim. 


\section{The FOBRIDGE project - the case study}

The FOBRIDGE is a scientific project co-financed by The National Centre for Research and Development [10]. The aim of this research was to create a novel solution for pedestrian and bicycle bridge which allows easy transportation, short production time and assembling without heavy equipment. In addition, it should be environmentally friendly and easy to recycle. This study was realized during three years (2012-2015). The structure was designed under the research grant realized by consortium of Gdansk University of Technology (leader), Military University of Technology in Warsaw and the private company ROMA Co Ltd. The group of researchers created the single-span, 14,5 m long, shell footbridge made of sandwich panels. These sandwich panels consist of GFRP laminates (outer skins) and a foam (core). The material used for a core is the polyethylene terephthalate, commonly called PET. This makes recycling of a structure much easier in the end of life phase. The proposed structural solution allows the use of already recycled material obtained from plastic packages in the production phase. The infusion process, used for manufacturing, allows to produce the whole structure in one part, without any additional joints or fasteners. Additionally, it minimizes environmental impact, due to the fact that a resin flow is applied in a vacuum. The standardized design and infusion technology also lead to cost reduction, [11]. The final product is a shell-type sandwich structure with U-shape cross section, fig. 4.

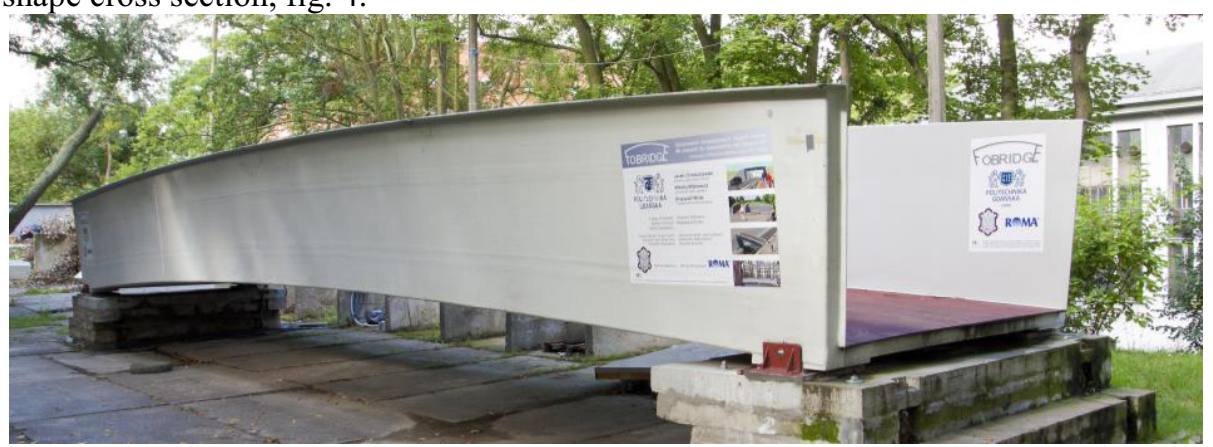

Fig. 4. Side view and cross section of the footbridge.

The main advantages of the considered footbridge are durability, dynamic resistance and incombustibility. Moreover, is easy to install because of its light weight (mass of 3,2 $t$ ) and does not require any laborious and heavy maintenance work. Also, during the service life any replacement activities are not required. For more information see also [12]. From the ecological point of view the FOBRIDGE solution includes all benefits, which are discussed in previous paragraphs. Also, during the end of life phase, the foam may be crushed and glass fibres can be reclaimed. In general, around $60 \%$ of materials which come from the entire structure could be reused.

\section{Conclusions}

The paper describes some possible applications of FRP composites in bridges from the environmental impact point of view. It is a response for contamination problems caused by a large amount of energy consumption and resource utilization. On the other hand, the FRP solution matches to a modern engineering, which aim is to reduce time of construction process and use of materials, and to minimize environmental pollution. The presented cases prove a huge potential for sustainability of the FRP use in civil engineering. Very good mechanical properties of FRP composites, like low volume weight and relatively high 
strength and stiffness at the same time, allow to achieve potential benefits for sustainable solution. Light weight enables fast transportation, allows to reduce traffic disruption, and the installation process become quick and simple. Moreover, future improvements for composite materials should decrease theirs embodied emissions.

The carbon emission is another very significant aspect in term of contamination problems. Traffic diversions, transportation types or embodied carbon of any new material are main factors, that should be considered to evaluate carbon emission. However, to make a good assessment of the environmental impact, it is necessary to consider all life cycle of analysed structures. In general, three main phases can by distinguished: construction, maintenance of a new superstructure and demolition. It is worth to note, that the application of FRP structural components in bridge structures do not exceed even 40 years. According to this, the end of life phase never has been reached and investigated.

To protect the environment, it is necessary to use recycling methods. Good waste manage provides very efficient recovery of used materials. FRP structures allow to reuse a huge part of their components by mechanical or incineration methods.

\section{References}

1. J.R. Duflou, Y. Deng, K. Van Acker, W. Dewulf, Do fiber-reinforced polymer composites provide environmentally benign alternatives? A life-cycle-assessmentbased study, (MRS Bulletin, 27 (2012)

2. C. Zhang, Life cycle assessment (LCA) of fibre reinforced polymer (FRP) composites in civil applications, Eco-efficient construction and building materials, (2014)

3. R. Sonnenschein, K. Gajdosova, I. Holly, FRP Composites and Their Using in the Construction of Bridges, Procedia Engineering, 161, 447-482 (2016)

4. http://www.cotswoldcanals.net/photo_page.php?idx=490

5. V. Mara, R. Haghani, P. Harryson, Bridge decks of fibre reinforced polymer (FRP): A sustainable solution, Construction and Building Materials, 50, 190-199 (2014)

6. L.S. Lee, R. Jain, The role of FRP composites in a sustainable world, Springer (published online : 2009)

7. G.P. Hammond, C.I. Jones, Embodied energy and carbon in construction materials, (2008)

8. S.J. Pickering, Recycling technology for thermoset composite materials - current status, Composites Part A : applied science and manufacturing, 37, 1206-1215 (2006)

9. R. Liang, G. Hota, Fiber-reinforced polymer (FRP) composites in environmental engineering application, Developments in FRP composites for civil engineering, 16 (2013)

10. M. Miśkiewicz, R. Okraszewska, and Ł. Pyrzowski, Composite footbridge - synergy effect in cooperation between universities and industry, ICERI2014: 7th International Conference of Education, Research and Innovation, ICERI Proceedings, Seville, Spain, 2897-2903 (2014)

11. M. Miśkiewicz, Ł. Pyrzowski, J. Chróścielewski, K. Wilde, Structural Health Monitoring of Composite Shell Footbridge for Its Design Validation, Baltic Geodetic Congress, Gdansk, Poland (2016)

12. J. Chróścielewski, M. Miśkiewicz, Ł. Pyrzowski, B. Sobczyk, K. Wilde, A novel sandwich footbridge - practical application of laminated composites in bridge design and in situ measurements of static response, (to be published) 